\title{
Libros de letras y letras en el libro: anotaciones caligráficas en manuales y artes de escritura (siglos XVI-XVIII)
}

\author{
Diego Navarro Bonilla* \\ Cristina Muñoz Vela**
}

Artículo recibido:

24 de junio de 2020

Artículo aceptado:

5 de octubre de 2020

Artículo de investigación

\section{Resumen}

El estudio material de los contenidos impresos en los tratados de caligrafía y las artes de escritura de la Europa moderna revitaliza el alcance y significación de sus anotaciones manuscritas marginales para comprender múltiples aspectos ligados con la recepción y uso real de estos materiales de aprendizaje escriturario por emulación. Como parte de una investigación de mayor alcance, este artículo se centra en la dialéctica entre el tratado impreso y las múltiples señales manuscritas imitativas de uso efectivo de aquellos ejemplares, lo que sugiere un conjunto de prácticas tradicionalmente consideradas secundarias o de importancia

* Departamento de Biblioteconomía y Documentación, Universidad Carlos III de Madrid, España dnavarro@bib.uc3m.es

** Universidad Carlos III de Madrid, España 100316269@alumnos.uc3m.es INVESTIGACIÓN BIBLIOTECOLÓGICA, vol. 35, núm. 87, abril/junio, 2021, México, ISSN: 2448-8321 pp. 107-128 
limitada pero imprescindibles para reconstruir la historia de la cultura escrita.

Palabras clave: Marginalia; Caligrafía; Marcas de Procedencia; Prácticas de Lectura

Books of letters and letters on the book: calligraphic annotations in treatises and arts of writing (16-18th centuries)

Diego Navarro Bonilla and Cristina Muñoz Vela

\begin{abstract}
The material study of the features of early modern printed contents in the calligraphic treatises and arts of writing in Europe revitalizes the scope and significance of its marginal handwritten annotations in order to understand multiple aspects related to the reception and real use of these scriptural learning materials by emulation. As part of a more extensive research, this article focuses on the dialectic between the printed treatise and the multiple imitative handwritten signs of effective use of these examples, which implies a set of practices traditionally considered secondary or of limited importance but which are essential to reconstruct the history of written culture.
\end{abstract}

Keywords: Marginalia; Calligraphy; Doodles; Provenance Marks; Reading Practices

INTRODUCCIÓN: LIBROS DE ESCRITURA Y ESCRITURA EN LOS LIBROS

$\mathrm{E}^{\mathrm{n}}$

n la muy barroca dedicatoria al infante don Carlos de Austria de la termaestro Pedro Díaz Morante recordaba la necesidad de innovar pero mirando con respeto a quienes antes que él habían cultivado exitosamente el arte de la escritura. Siendo consciente de que él no se limitaba a reproducir, sino a inventar una original forma adaptada a las necesidades prácticas de quienes requerían de la escritura (Arte nueva), también ponderaba positivamente las enseñanzas de quienes, aunque “autores de lo antiguo" décadas atrás, 
habían sido considerados verdaderos maestros en el arte caligráfico hasta la fecha (Arte vieja). Eso equivalía a situar a Juan de Icíar, Pedro de Madariaga y Francisco Lucas entre la nómina de eximios autores, si bien apegados a una forma de enseñar la escritura muy dependiente de la secuencia ordenada de trazos que definían el ductus y que a comienzos del XVII comenzaba a cuestionarse gracias al estilo de letras trabadas o ligadas como consecuencia de una imparable cursividad funcional.

Por el contrario, a tenor de sus experiencias docentes con múltiples alumnos y discípulos, presentes y distantes, no parecía haber entrado en crisis una práctica silenciosa que seguía vigente y bien ponderada como era la de aprender a escribir con el libro delante. Así al menos se desprende de su testimonio cuando, no sin orgullo personal, recordaba lo conseguido con el hijo y heredero del Conde de Santisteban del Puerto (Segunda parte..., Madrid, Luis Sánchez, 1624, f. 2v), quien "con solo mi libro primera parte, escribiéndolo solo con el dicho libro en su casa, se hizo muy lindo escribano en breve tiempo". Esta forma rápida y fiable de aprender con el libro como objeto que contiene el acceso a las capacidades, custodio en sus páginas y láminas de una suerte de arte fascinante rápido y efectivo en el aprendizaje de la escritura, se sumaba a la enseñanza de la caligrafía a distancia, algo que al parecer tampoco le planteaba demasiados problemas al gran Díaz Morante. Sorprende ya en pleno siglo XVII una suerte de innovador teleaprendizaje y, de hecho, discípulos que seguían su método desde Sevilla le iban enviando a Madrid pruebas y ejercicios mientras él, desde la corte, procedía a su lectura y corrección devolviéndolas por la estafeta ("y yo les corregía en las márgenes de ellas") en una singular puesta en práctica del célebre "corre manuscrito" que estudiase detalladamente Fernando Bouza Álvarez (2001). En todos estos ejemplos era fundamental, por tanto, encontrar un nexo de unión entre el maestro virtual y el discípulo. Así, el propio libro o manual serviría de referencia en lo relativo a sus contenidos, pero también de tentación de uso directo, en tanto que objeto generoso en espacios de escritura y receptivo a cuantos trazos y pruebas mostrasen, por imitación práctica con las láminas estudiadas, los avances en la pericia caligráfica: "En cierto modo, el manual de caligrafía usurpó al maestro, pues como muchos señalan, el libro mismo podía enseñar el arte de escribir, sin necesidad de escuela. El escribiente se sustituía por el libro" (Egido, 2003: 49). El caso más novedoso de ese aprendizaje directo seguiría siendo el del misterioso Andrés Brun y su Arte muy provechoso para aprender a escribir (1583 y 1612), con sus láminas de letras huecas para ser rellenadas (Martínez Pereira, 2004: 247). En suma, de todo 
ello se desprende un interrogante que constituye la principal guía de estas páginas, dejando a un lado la compleja existencia de láminas impresas sueltas con muestras para el aprendizaje de la escritura: ¿ escribir con el libro o sobre el libro?

En el amplio discurso sobre las multiformes prácticas y los resultados del aprendizaje de la escritura, así como las que documentan directamente la lectura, se ha prestado una atención desigual a los rastros manuscritos dejados específicamente sobre aquellos tratados impresos que servían de apoyo e inspiración directa en el proceso de adquisición de las primeras destrezas escriturarias y caligráficas (Barbier, 1998: 269). A su vez, este estudio sobre las anotaciones manuscritas forma parte de esa historia social del libro glosada por Iveta Nakládalová $(2013: 6,8)$ en la que el texto impreso deja de ser una abstracción para reivindicar "las diferentes maneras en las que se aprehendían y manejaban los textos"; entre ellas, estas intervenciones de un lector que situamos entre las más fértiles para propiciar el debate en torno a las prácticas y las experiencias tangibles de la lectura (Chartier, 1992). Por tanto, la anotación marginal no es sólo recepción sino también acto creativo que define una experiencia individual de lectura, máxime en el caso de los tratados de caligrafía donde el componente práctico y de emulación directa que sugieren las láminas de alfabetos y exempla fue muy intenso. Incluso podría hablarse de la provocación visual que dichas muestras generaban en un lector dispuesto a tomar sin dilación la pluma para probar su capacidad de reproducción directamente, sobre el mismo ejemplar.

Bien fuera para iniciar una carrera llamada a destinos burocráticos o secretariales en plena consolidación del Estado Moderno o para simplemente adquirir los necesarios rudimentos del trazo en escuelas alejadas de los brillos cortesanos, para atender cuentas y razones domésticas, la interacción entre materialidad del libro impreso y los ejercicios manuscritos por emulación encuentran un punto de encuentro en estas páginas. De hecho, este artículo forma parte de una investigación más amplia centrada en la identificación, caracterización y análisis de todas las intervenciones manuscritas halladas en manuales de escritura y caligrafía españoles impresos durante los siglos XVI al XVIII: desde simples subrayados o señales de lectura hasta eruditos comentarios marginales sobre el arte caligráfico. Ana Martínez Pereira (20032004) incidió en la doble y problemática clasificación de estos manuales para aprender a escribir: como manual práctico y como obra de arte. Aquí nos centramos en la primera consideración y únicamente se aborda uno de los múltiples trabajos posibles derivados del análisis de los marginalia y es el que 
convierte implícitamente a estos tratados impresos del arte de escritura en cuadernos manuscritos improvisados, próximos a una suerte de artefacto integrado: manual impreso por un lado y hojas sobrantes con pruebas, trazos y ejercicios manuscritos ocasionales por otro. Su explotación e incorporación sistemática al conjunto de fuentes históricas que apuntalan la historia de la cultura escrita constituyen un objetivo esencial.

Se trata, por tanto, de una aportación a la historia de la caligrafía hispana desde la bibliografía material, que pocas veces antes había contemplado estas anotaciones localizadas en ejemplares impresos (Becker, 1997: XI). Con ella se trata de clarificar cuestiones relativas al uso efectivo y a la transmisión y recepción de los manuales de teoría y práctica caligráfica desde mediados del siglo XVI (Egido, 2003; Martínez Pereira, 2006; Gutiérrez Cabero, 2015). Una investigación sobre la historia caligráfica hispana que se suma a los renovados impulsos a través de exposiciones y selecciones bibliográficas como la que tuvo lugar en la Biblioteca Nacional en Madrid en 2015, recopiladas bajo el título Caligrafía española: el arte de escribir. Aquí se han localizado numerosos ejemplares anotados que inciden en la relevancia de cubiertas, hojas de guarda, márgenes y cuantos espacios de papel en blanco dentro de la materialidad del impreso (Athanassoglou-Kallmyer, 2019) se convirtieron en áreas gráficas de práctica y aprendizaje por imitación con dispares habilidades escriturarias de los tipos de letra, muestras y abecedarios propuestos por autores que irían configurando el canon de la teoría y práctica caligráfica moderna.

Como señaló Wolfgang Iser (1980), el estudio de una obra es también el análisis de las acciones llevadas a cabo para responder a ese texto en dos planos: el artístico (texto del autor) y el estético (realizaciones del lector). Así, los "blancos" de un texto impreso son partes esenciales no sólo de su propia estética material en cuanto suministradores de "aire" tipográfico, sino también de estos procesos de comunicación manuscrita (Fleming, 2016). Por otra parte, estos espacios en blanco sobrantes invitan e incitan a su aprovechamiento para los propios usos del lector activo ("apurar el papel”, como se decía en torno a 1600). En el caso de tratados de profunda practicidad, como los caligráficos, esa invitación al aprendizaje de las muestras por vía de repetición no es abstracta (la de la mera página en blanco), sino concreta: la de los ejercicios, variantes y modelos propuestos en la propia obra. Estas muestras de escritura por emulación "con el libro y sobre el libro" aquí desplegadas son, asimismo, expresiones fundamentales de una suerte de autoaprendizaje rastreable no sólo en España, sino en toda la Europa moderna (Figuras 1a y 1b). 


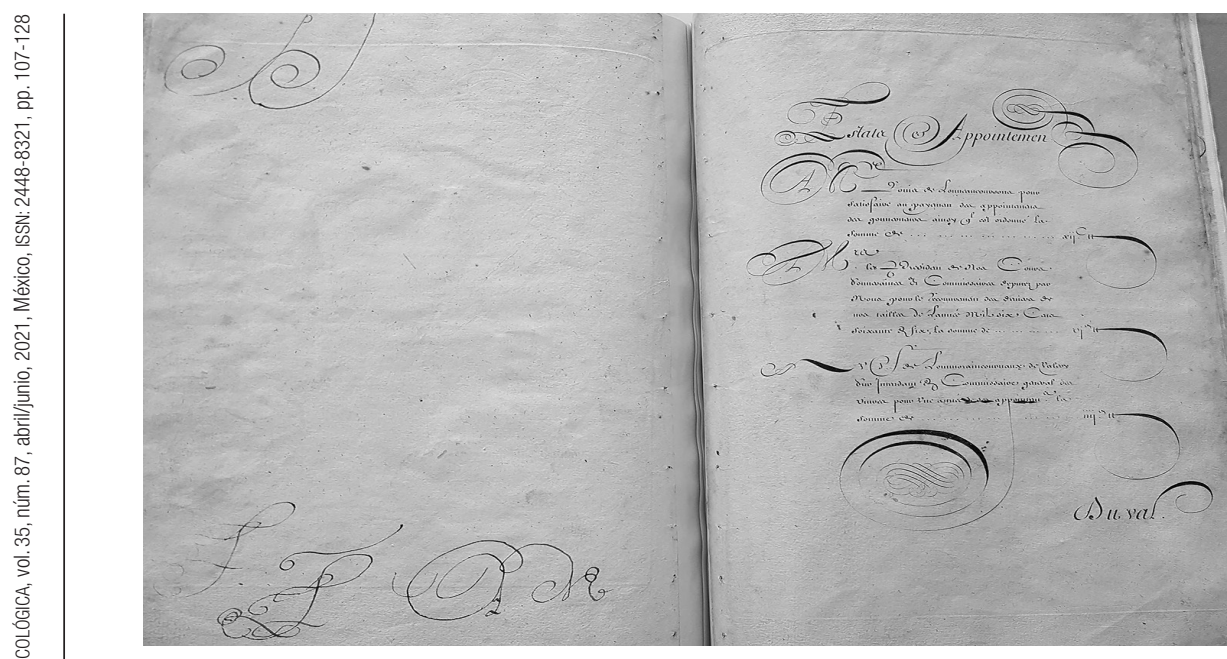

Figura 1a. Nicolás Duval, Le trésor des nouvelles escritures de finances et italiennes bastardes [... . . París, F. Jollain, 1719. Madrid, Imprenta Municipal-Artes del Libro. Colección Del Olmo \& Vilas, D0\&V 1049
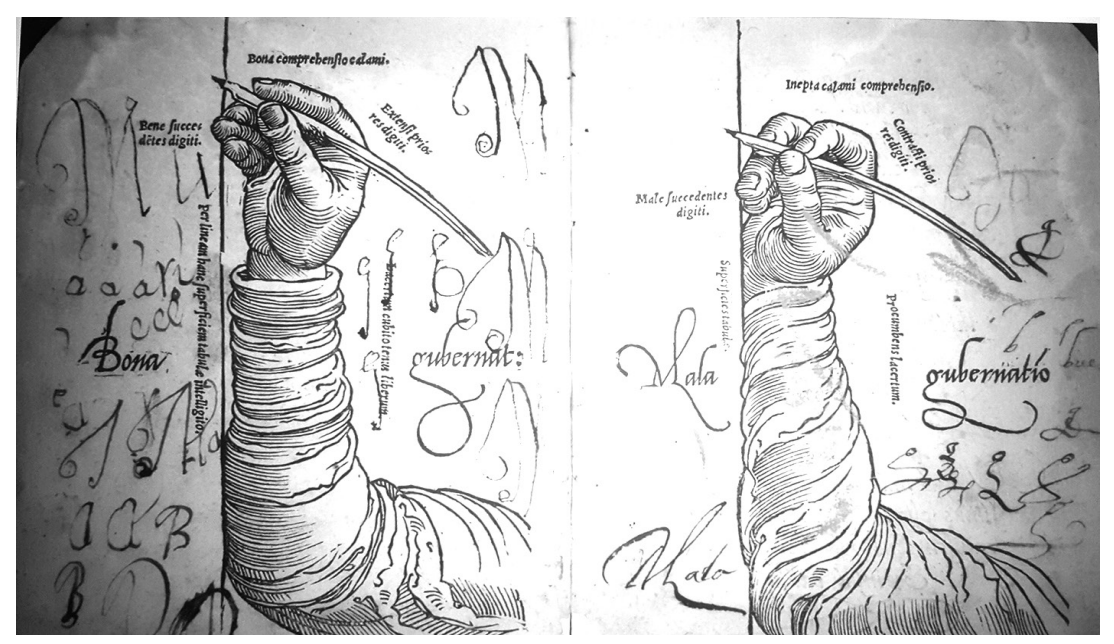

Figura 1b. Gerard Mercator, Literarum latinarum quas italicas cursoriasque vocant, scribendarum ratio, Antuerpiae: excudebat Joannes Richard, 1549. BNE, R/697. Accesible: Biblioteca Digital Hispánica

\section{ANOTACIONES EN ESPACIOS SECUNDARIOS Y MARGINALIA: CARACTERIZACIÓN Y EXPLOTACIÓN}

Armando Petrucci (1999: 35) insistió con frecuencia en que "habría que desarrollar atentas investigaciones [...] sobre los objetos de lectura, es decir, los 
libros, manuscritos o impresos, para reconstruir, a través de las notas de posesión y de las anotaciones de lectura, la historia y la individualidad de sus propietarios y usuarios". En parecidos términos, Gimeno Blay (1995) recordó que "las escrituras, contrahechas y descuidadas, no sugerían campos de análisis, ya que nuestros paleógrafos se hallaban cautivados por las escrituras de nuestros antiguos códices medievales o la de los privilegios reales y escrituras más solemnes”. Glosas, apuntes, comentarios escritos en cualquier superficie disponible del volumen configuran todo el universo de los marginalia, sus funciones, materializaciones y utilidades para la reconstrucción bibliográfica (Stoddard, 1985; Alston, 1994; Pearson, 1994; Rosenthal, 1997).

Profundizar en el conocimiento de las anotaciones manuscritas implica preguntarse acerca de la intencionalidad de las mismas y requiere indagar en los impulsos por escribir y aprovechar deliberadamente esos espacios propicios al comentario manuscrito, asunto de enorme complejidad y no exento de problemática (Jackson, 2001). No olvidemos, además, que estas prácticas escriturarias "al margen" no siempre ofrecen un resultado propiamente derivado del intenso trabajo intelectual. Dicho de otro modo, habría que diferenciar en función del grado de reinterpretación del texto impreso original entre anotar, glosar o simplemente usar los espacios de escritura disponibles (Jahjah, 2014). Además, con independencia del grado de transgresión aparente (Gimeno Blay, 2010) que textos procaces o dibujos mostrasen en márgenes sobrantes, la alteración de ese orden formal de todo texto primitivo surgido de las prensas solía responder a una motivación material y económica: utilizar de algún modo los numerosos blancos de papel desaprovechados en un libro impreso. Acerca de las motivaciones que guían estas prácticas, Navarro Bonilla (2003: 245) expresa que la "interrelación surgida en el acto de lectura entre el texto y el lector, unida a la disposición tipográfica y material del contenido son factores que favorecen la libertad de intervención del lector en la página donde se plasma un texto". En todo caso, como bien señalan María Victoria Martínez y Natalia Ortiz sobre la problemática ambigüedad y limitación de estas anotaciones (2018: 47): "no fueron (casi nunca) pensadas para ser entendidas por otros lectores. La marginalia, en todo su espectro, es fragmento de pura subjetividad”.

Por su carácter marginal frente al núcleo preeminente del texto impreso y por su general valoración como "muestras de menor importancia", estas intervenciones manuscritas han ocupado un lugar específico dentro de las llamadas "escrituras ordinarias", según la denominación que estableciese Daniel Fabré (1993, 1997; Sáez, 1998). No obstante, a pesar de la denominación habitual de "escrituras marginales", por situarse generalmente al margen del texto impreso, conviene a nuestro juicio introducir el término más preciso de 
“escrituras secundarias”, habida cuenta de que los márgenes del libro impreso son acaso el espacio más propicio para la práctica manuscrita pero no el único, ya que son muchas otras las posibilidades (cubiertas, hojas de guarda, recto y vuelto de portada, hojas de respeto, etc.) con que la materialidad, formato y morfología interna del libro impreso determina los modos de lectura y permite acoger la intervención manuscrita del lector o del escribiente ocasional con trazos derivados de las miradas puestas sobre el texto principal (Martínez y Ortiz, 2018). Diferente denominación sugirieron Bernard Rosenthal (1999) y Giuseppe Frasso (1995) con el término postillati. Más recientemente, la tesis de Marc Jahjah (2014: 75-80) plantea una interesante vuelta sobre las anotaciones marginales incluyendo un estudio terminológico desde el siglo XVI hasta la actualidad, pasando por Coleridge, y una distinción entre "marginalia de lectura", a las que pertenecería la mayor parte de las muestras aquí estudiadas, y "marginalia de confection”, anotaciones y señales más propias del proceso de edición en un taller de imprenta.

La presencia de anotaciones manuscritas en impresos da pie a estudios de naturaleza paleográfica, morfológica, de autoría, género, temática, circulación, ubicación, etc. Véase, por ejemplo, el interés del enfoque comparativo que hemos seguido para estudiar las anotaciones caligráficas imitativas en dos ejemplares anotados del mismo tratado de José de Casanova, Primera parte del Arte de escrivir todas formas de letras, 1650, en el que diferentes manos, en momentos muy dispares, nos hablan de cómo el tratado se convierte en campo de pruebas y experimentación caligráfica muy diversa: bien reproduciendo la lámina de la derecha en el blanco de la izquierda (Figura 3), bien aprovechando márgenes en secuencia desordenada y libre de rúbricas y ringorrangos sin solución de continuidad (Figura 2). En el primer caso, además, con el valioso añadido de la consignación del autor del ejercicio caligráfico, con inusual expresión de su data crónica y tópica: "Domingo Monreal, Aniés (Huesca), 31 de mayo de 1769".

Asimismo, estos estudios promueven una actualización de la descripción bibliográfica normalizada internacional, que debe dar respuesta a estos descubrimientos manuscritos marginales hallados en un ejemplar impreso concreto que enriquecen su análisis y contribuyen a perfilar aspectos relacionados con la denominada "fortuna del códice" (Rosenthal, 1997; Lucía Megías, 2002; Heitzmann, 2015). También ofrece la anotación manuscrita un poderoso argumento para reducir las ambigüedades del debate entre leer libros o simplemente poseerlos, asunto éste de larga tradición cultural. 


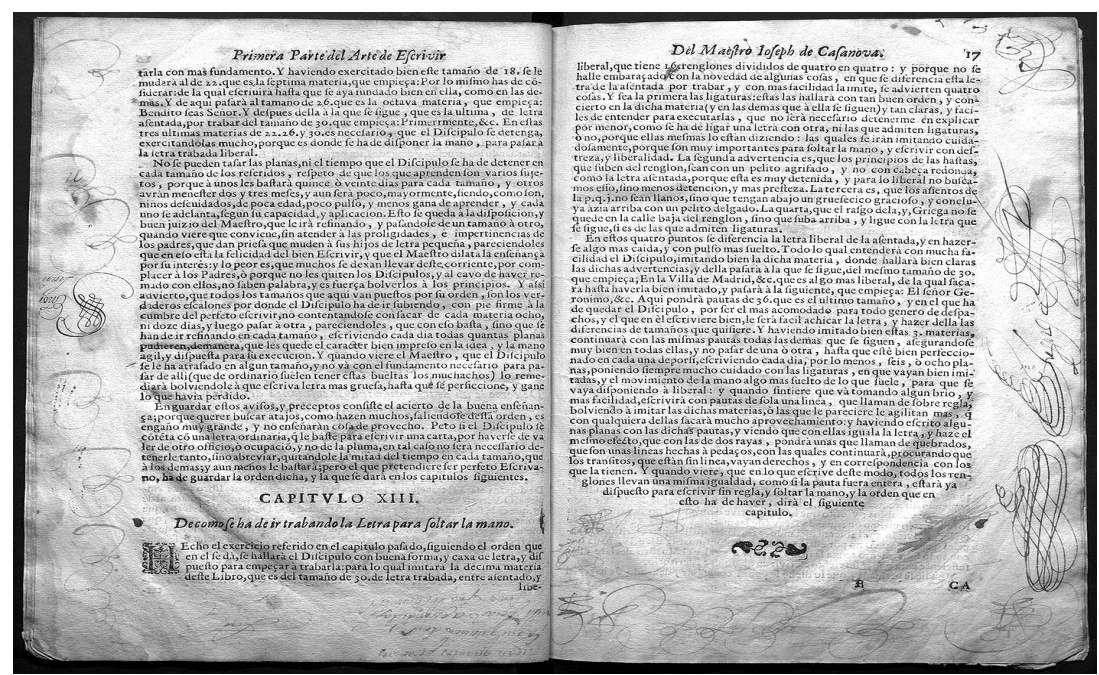

Figura 2. Ocupación del blanco marginal y expresión de libertad con florituras y rasgueos caligráficos. José de Casanova, Primera parte del Arte de escrivir [...], 1650. Biblioteca Universitaria de Zaragoza,

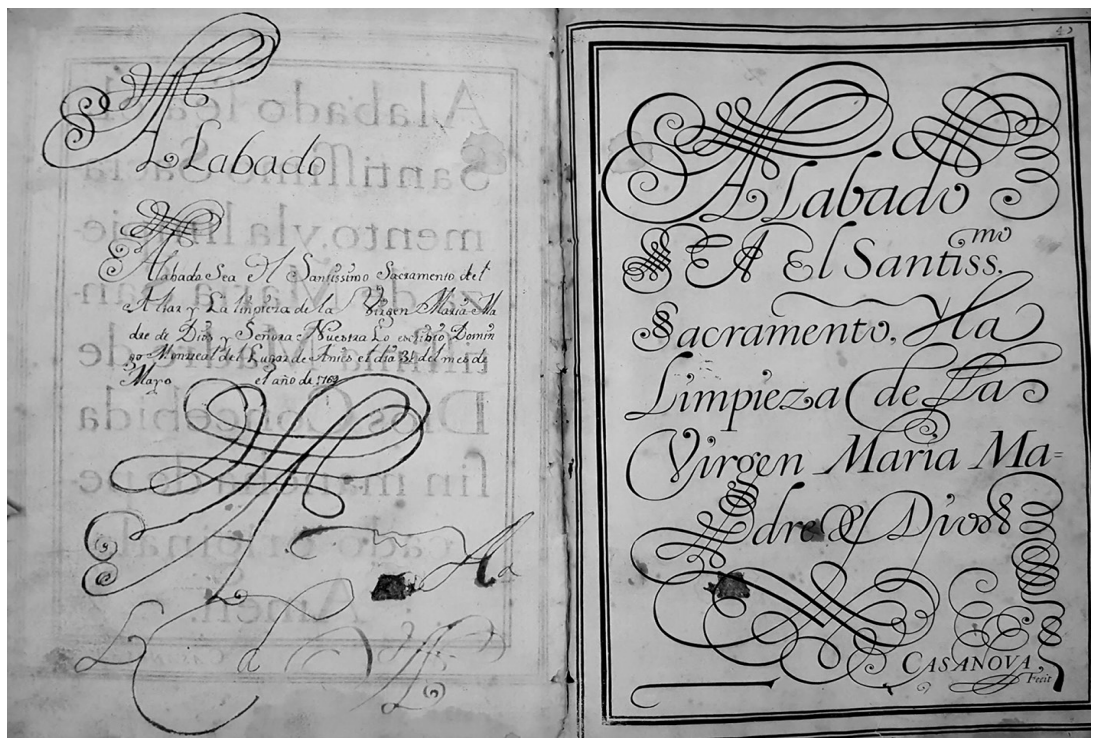

Figura 3. Misma obra, diferente ejercicio de autoaprendizaje caligráfico por imitación. José de Casanova, Primera parte del Arte de escrivir [... ], 1650. Madrid, Imprenta Municipal-Artes del Libro. Colección Del Olmo \& Vilas, D0\&V 1008 
En esta investigación, el tratado de caligrafía o bella escritura se reformula, convirtiéndose en un artefacto de reaprovechamiento material de sus espacios secundarios, para descubrir una nueva perspectiva que lo define según las múltiples intervenciones emulativas que albergan, imitando los ejemplos y muestrarios de tipos de letra para enseñar el fundamento y el arte de la caligrafía en España. Estos tratados se fueron publicando en la España del Quinientos con gran profusión y alcance (Martínez Pereira, 2003-2004), al igual que venía sucediendo con los maestros de "perfecta escritura" procedentes de Alemania o Italia (Doede, 1958; Morison, 1962; Johnson, 1950; Bonacini, 1953) conservados en bibliotecas y colecciones por todo el mundo (Becker, 1997). El libro impreso, en suma, como depósito de marcas de uso y propiedad; unas veces mínimas (repeticiones de fórmulas jurídicas, invocaciones, oraciones, pruebas de escritura, dibujos, garabatos, fragmentos literarios), otras veces máximas (glosas técnicas completas, comentarios a favor o en contra-adversaria- de lo dicho por el autor, ampliación de datos sobre autor y obra, etc.). La huella manuscrita de maestros expertos en el arte de la caligrafía que anotaron los tratados anteriores o coetáneos sugiere una viva recepción de aquellas obras, sin faltar laudas, pero también virulentos ataques in absentia.

Los primeros resultados de esta fase exploratoria se basaron en la inspección directa de 245 volúmenes correspondientes a 24 títulos de tratados de caligrafía y artes de escribir (Anexo), repartidos en 18 depósitos documentales de Madrid y Aragón. De este total de volúmenes examinados y analizados, la muestra final quedó circunscrita a los 126 ejemplares que contienen algún tipo de intervención manuscrita (51,42\%). De entre aquellos autores cuyas obras sí contienen anotaciones marginales, Juan de Icíar se sitúa a la cabeza con un $17,46 \%$ sobre el total (Tabla1).

\begin{tabular}{|l|c|c|}
\hline \multicolumn{1}{|c|}{ Autores } & $\begin{array}{c}\text { No. de ejemplares } \\
\text { con an.mss. }\end{array}$ & \% del total \\
\hline Juan de Icíar & 22 & 17,46 \\
\hline Francisco Lucas & 18 & 14,28 \\
\hline Francisco Xavier de Santiago Palomares & 15 & 11,9 \\
\hline Juan Claudio Aznar de Polanco & 9 & 7,14 \\
\hline Pedro Díaz Morante & 9 & 7,14 \\
\hline José de Casanova & 9 & 7,14 \\
\hline Diego Bueno & 8 & 6,34 \\
\hline
\end{tabular}




\begin{tabular}{|l|c|c|}
\hline Joseph Anduaga y Garimberti & 8 & 6,34 \\
\hline Cristóbal Rodríguez & 7 & 5,55 \\
\hline Pedro de Madariaga & 5 & 3,96 \\
\hline Ignacio Pérez & 5 & 3,96 \\
\hline Lorenzo Ortiz & 5 & 3,96 \\
\hline Juan de la Cuesta & 3 & 2,38 \\
\hline Francisco Asensio y Mejorada & 2 & 1,58 \\
\hline Pedro Flórez & 1 & 0,79 \\
\hline Domingo María de Servidori & 0 & 0 \\
\hline & 126 & 100 \\
\hline
\end{tabular}

Tabla 1. Número de ejemplares con anotaciones manuscritas por autor

Los tratados de caligrafía analizados que se imprimieron en la segunda mitad del siglo XVI fueron anotados con mucha más frecuencia que los del siglo XVII. Al llegar al XVIII se vuelve a observar un aumento en las prácticas de anotación marginal. En los tres siglos, las principales muestras de intervención manuscrita seguían siendo las pruebas de escritura y las marcas de propiedad y no tanto la anotación erudita.

Si volvemos sobre el discurso de las prácticas de aprendizaje, en el método propuesto por Díaz Morante se repite continuamente la idea de la exercitatio por medio de la imitatio. Lo que no se especifica es dónde o sobre qué material se deben llevar a cabo esos ejercicios escriturarios, mientras se aprendían los fundamentos de cada tipo de letra que definía el canon gráfico de los siglos XVI y XVII. Reproducir los ejemplos en las mismas hojas de los abecedarios en letra bastarda, o grifa, o redonda se basaba en una suerte de estudio imitativo, gráfico que quedaba inserto en la memoria visual ("imprimir en la mente" lo denomina Santiago Palomares, 1776: XXI) para, a continuación, volcarlo en íntima conexión de mente y mano: "Lo primero que debe hacer el que desea ser buen escribano es imitar todos los abecedarios, borradores y materias de letra trabada que se contienen en este libro" (27), como recordaba Díaz Morante en su ya citada tercera parte.

Se comprueba esta secuencia de reproducción por imitación en un anotadísimo ejemplar del Arte de escribir de Francisco Lucas en edición de 1580. Receptor de diversas manos, en múltiples momentos de escritura, incluso datados (lo que atestigua la clara transmisión del ejemplar como manual de aprendizaje entre siglos), descubrimos a una Nicolasa Muñico la menor [sic] que pone en práctica el estudio de las letras mayúsculas de la bastarda propuesta por Lucas, con desigual fortuna caligráfica (Figuras $4 a$ y $4 b$ ). 


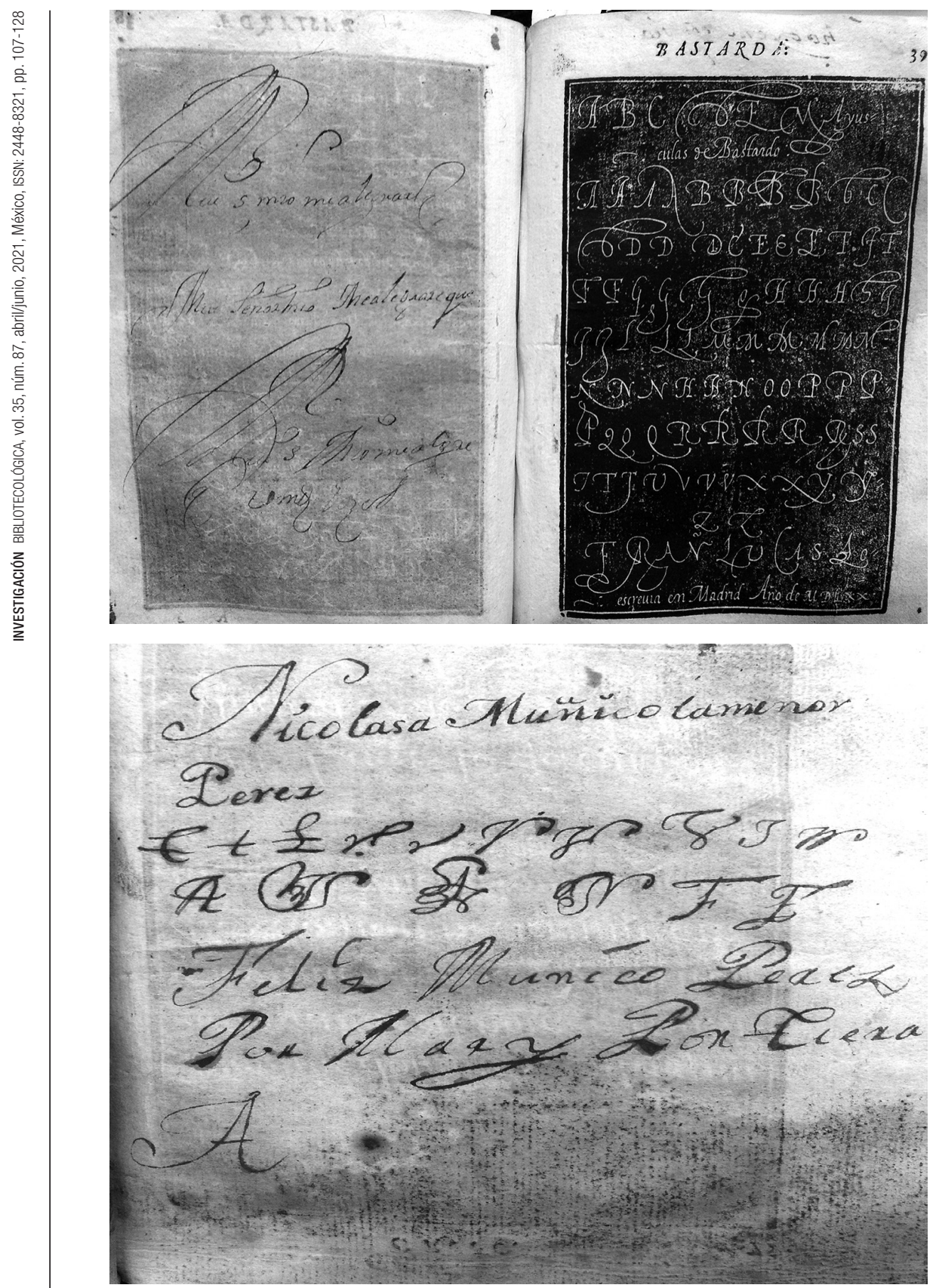

Figuras 4a y 4b. Ejercicios de mayúsculas en letra bastarda de Nicolasa Muñico. Francisco Lucas, Arte de escrevir [... ], Madrid, Francisco Sánchez, 1580. Colección particular de los autores 
Dentro de las múltiples intervenciones manuscritas, las tipologías más representadas han sido, por este orden y sin apenas variaciones desde el siglo XVI, las pruebas del instrumento de escritura, los ejercicios caligráficos por reproducción de los grabados y los ex libris manuscritos y las marcas de propiedad. De hecho, encontramos un indicador de función utilitaria de estos ejemplares al hallar en muchas ocasiones los múltiples rasgueos y ejercicios estrictamente preparatorios de la pluma, con las habituales series de repeticiones alfabéticas y consignación de fórmulas de salutación, jurídicas o invocaciones religiosas, manchas de tinta y otros indicios, que hacen pensar en el aprovechamiento activo del ejemplar impreso para realizar sobre sus páginas una serie de ejercicios preparatorios caligráficos. Ejercicios que, en función de su grado de competencia y habilidad, sugieren espacios de practicidad en el arte de escribir: desde simples muestras escolares hasta afinamientos de pluma, comprobación del flujo de tinta y ejercitación de la mano como acciones preparatorias previas al trabajo burocrático más avanzado.

\section{No sólo TRATADOS DE CALIGRAFÍA}

Ahora bien, las pruebas de escritura y las huellas que muestran prácticas en el aprendizaje de la caligrafía por imitación directa no fueron exclusivas de estos tratados o manuales caligráficos (Cruz Pascal, 2001-2002) ni tampoco de otras formas documentales, ya que registros, procesos, protocolos, cartularios y diversas tipologías manuscritas atesoran a su vez infinidad de pruebas caligráficas pendientes de sistematización y plantean interrogantes acerca del aprovechamiento de estos otros espacios en blanco, incluso en fechas alejadas entre la producción original administrativa y la anotación o anotaciones marginales recibidas (Boscá Codina, 1990; Els Ninots, 1999; Montaner Frutos y Navarro, 2006; Cía Álvaro, 2010). Sucede, por ejemplo, en el protocolo del notario zaragozano Alfonso Francés. Este registro está fechado en 1495 (Figura 5), pero fue receptor en sus hojas sobrantes de numerosos ejercicios caligráficos posteriores, como consecuencia, muy probablemente, del traspaso habitual de las notas y volúmenes de notarios fallecidos a otros notarios de generación en generación. 


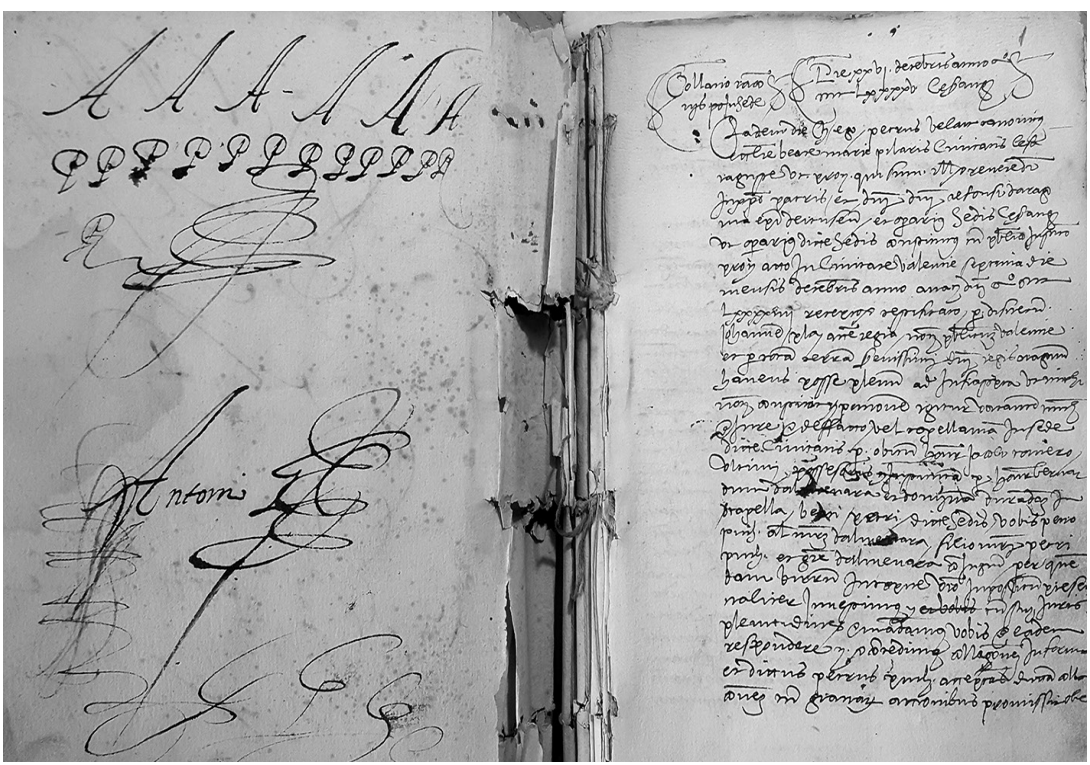

Figura 5. Pruebas caligráficas de los siglos XVI-XVII en el protocolo notarial de Alfonso Francés, Zaragoza, original de 1495. Archivo Histórico de Protocolos Notariales de Zaragoza, nº 2202

En infinidad de impresos de temática no caligráfica se hallarán intervenciones manuscritas marginales con ejercicios y reproducciones de tipos de letra, rasgueos, florituras, volutas y, como denominan Javier García del Olmo y Ricardo Rousselot, "ringorrangos", en una muestra más del intento por dominar el espacio de escritura mediante el trazo armónico. Más ejercicios de escritura precaligráfica serán realizados naturalmente en el transcurso del aprendizaje de las primeras letras sobre beceroles, cartillas y silabarios (Infantes y Martínez Pereira, 2003; Castillo Gómez, 1996). Y sirva como ejemplo el aprovechamiento de los amplios márgenes de una Biblia impresa en 1480 que acabaron siendo espacio de práctica escrituraria muy primitiva, con reutilización del ejemplar a varias manos en el seno de una escuela de Gómara (Soria), hasta llegar a 1723, tal y como rezan las sugerentes anotaciones (passim) dejadas en diciembre de aquel año por uno de sus escolares, llamado Francisco de Almajano (Figuras 6 y 7 ):

De la mano y pluma de Francisco Almajano, siendo discípulo de 12 mi señor maestro Juan Lázaro que enseña el arte de ler i es $\mid$ crivir y contar [...]. 

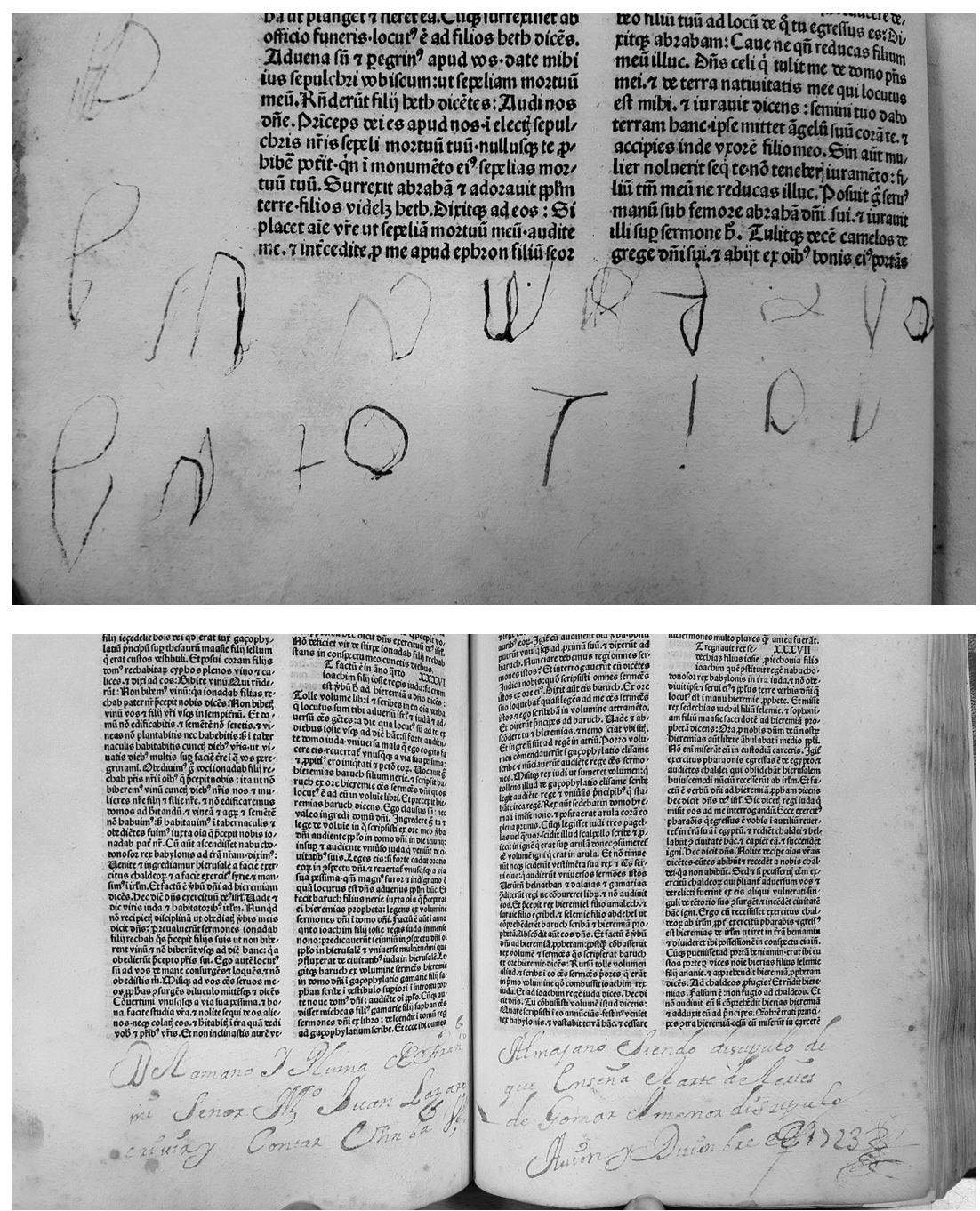

Figuras 6 y 7. Biblia latina, Venecia, F. Renner de Hailbrun, 1480. Soria, Biblioteca Pública del Estado, I-24

De igual modo, cabe preguntarse entonces acerca del empleo continuado de estos tratados de escritura como manuales de texto o muestras repetidas una y otra vez por diferentes lectores que aprendieron sobre sus páginas y grabados a imitar los trazos, unas veces simplemente dibujando las letras y otras reproduciendo de manera pautada y ajustada al ductus correspondiente el tipo de letra elegida. En contadas ocasiones, sí es factible determinar autoría (caso ya visto de Nicolasa Muñico) y, no sólo eso, sino edad y comentarios sobre la obra que un joven aprendiz está utilizando como modelo caligráfico: 
Francisco Javier de Santiago Palomares, Arte nueva de escribir inventada por... Pedro Diaz Morante, Madrid, Antonio de Sancha, 1776. RAE, 19-II-36. Anotación manuscrita: "Luis Miguel y Ruiz, de edad de 11 años imita al docto Pedro Díaz y Morante nada más que en imitar las letras que expresa el libro y él mismo hizo esta letra. Luis Miguel Ruiz. Rúbrica”.

El fenómeno de la reutilización de los libros impresos para ejercitar las aptitudes caligráficas sugiere la aplicación de un coeficiente de reaprovechamiento general, derivado del número de intervenciones posteriores al año de impresión llegando en algunos casos a transcurrir dos siglos ininterrumpidos sirviendo el mismo ejemplar como material que recibe múltiples y superpuestas prácticas de escritura. Estos sucesivos estratos de reescritura convierten a estos ejemplares empleados en este estudio en verdaderos registros arqueológicos de intervenciones, manos y pruebas de aprendizaje caligráfico sobre el libro (Figura 8).



Figura 8. Mención marginal izquierda al año 1829 en un ejemplar de Francisco Xavier de Santiago Palomares. Arte nueva de escribir [... ], 1776. Madrid, Imprenta Municipal-Artes del Libro.

Colección Del Olmo \& Vilas, D0\&V 1019 


\section{Conclusiones}

El análisis de las anotaciones manuscritas como trazas de uso efectivo dejadas en las páginas de los tratados de caligrafía impresos durante los siglos XVI al XVIII en España facilita los estudios sobre las prácticas de escritura, lectura, recepción, visibilidad y circulación para ampliar planteamientos, enfoques y fuentes tradicionales en torno a la historia del libro, de la lectura y la escritura durante la Edad Moderna. Como material impreso de carácter formativo, los tratados de caligrafía no escapan a la práctica extendida de la anotación manuscrita en sus espacios marginales y secundarios. Intervenciones comunes a cualquier otro impreso, como cuentas, señales de llamada, ex libris, precio, circunstancias de adquisición, procedencia o, simplemente, pruebas de escritura se encuentran también aquí profusamente representadas para contribuir a trazar la "fortuna del ejemplar". La gran mayoría de las anotaciones encontradas no sugieren una lectura con comentarios eruditos y profesionales, sino más bien un aprovechamiento material de sus páginas para ejercitar la práctica caligráfica enseñada en los muestrarios de letras de estos manuales en un proceso de autoaprendizaje por emulación. Así, desde esa perspectiva material, estas "artes de escritura" se convirtieron muchas veces (pero no en exclusiva) en improvisados cuadernos de ejercicios caligráficos informales, de uso cotidiano, siguiendo el modelo de las láminas impresas en ellos contenidas, tratando de imitarlas directamente. Tanto la tosquedad de algunos de los ejemplos localizados como la destreza y rapidez en algunas de las florituras caligráficas reflejan los dispares niveles de competencia gráfica rudimentaria, escolar o profesional, alcanzada en quien está tratando de imitar a los autores de referencia. Las sucesivas anotaciones manuscritas rastreables sobre un mismo ejemplar a lo largo de los siglos sugieren, además, su consideración como objeto referencial en una suerte de herencia generacional para el ejercicio de trazos y adornos caligráficos. En suma, todo un conjunto relevante de muestras generadas durante los diferentes estadios de la práctica escrituraria para acreditar sobre el mismo ejemplar la influencia de las formas gráficas que estos tratados ejercieron en los procesos de aprendizaje de los tipos de letra que constituirían el canon caligráfico de los siglos modernos. 
Esta investigación tiene su origen en la ampliación del trabajo de fin de grado que defendió Cristina Muñoz Vela en el Grado en Información y Documentación de la Universidad Carlos III de Madrid sobre anotaciones marginales generales en impresos antiguos, propuesto y supervisado por el doctor Diego Navarro Bonilla durante el curso 2016-2017. Se enmarca en el proyecto de investigación Del manuscrito a las pantallas: Memoria, artefactos y prácticas culturales (del siglo XV a nuestros días). Ministerio de Economía, Industria y Competitividad. Ref: HAR2016-76550P. Investigador principal: Dr. Enrique Villalba Pérez (UC3M). Agradecemos muy sinceramente al profesor Alberto Montaner Frutos (Universidad de Zaragoza) sus precisos comentarios. A Teresa de la Fuente y a Mercedes Melendo (Biblioteca Pública del Estado, Soria), Zulema Ledesma (Archivo Histórico de Protocolos Notariales, Zaragoza), Paz Miranda (Universidad de Zaragoza), Javier García del Olmo y Esther Vilas y a la Imprenta Municipal Artes del Libro de Madrid por todas las facilidades brindadas en la consulta y reproducción de las obras incluidas en este artículo.

\section{REFERENCIAS}

Alston, R. C. 1994. Books with manuscripts: a short-title catalogue of books with manuscripts notes in the British Library [...]. London: British Library.

Athanassoglou-Kallmyer, Nina. 2019. "Materiality, Sign of the Times". The Art Bulletin 101 (4): 6-7.

Barbier, Fréderic. 1998. "L'Histoire, L'Historien et la lecture". Gutenberg Jabrbuch: 269.

Becker, David P. 1997. The Practice of Letters: The Hofer Collection of Writing Manuals, 1514-1800. EEUU: Houghton Library of the Harvard College Library.

Biblioteca Nacional de España. 2015. Caligrafía española: el arte de escribir. Madrid: Biblioteca Nacional de España. Comisario: José María Ribagorda.

Bonacini, Claudio. 1953. Bibliografia delle Arti Scrittorie e della Calligrafia. Florence: Sansoni.

Boscá Codina, José Vicente. 1990. "Ejercicios de escritura en la Valencia medieval”. Historia de la educación: revista interuniversitaria 9: 303-310.

Bouza Álvarez, Fernando. 2001. Corre manuscrito: una historia cultural del Siglo de Oro. Madrid: Marcial Pons.

Castillo Gómez, Antonio. 1996. "Garabatos y ejercicios de escritura en un ejemplar del Tratado sobre la forma que se ha de tener en el oir de la misa de Alfonso el Tostado (Alcalá, 1511)". SIGNO. Revista de Historia de la Cultura Escrita 3: 193-201.

Chartier, Roger. 1992. El mundo como representación. Estudios sobre historia cultural. Barcelona: Gedisa.

Cía Álvaro, Ion. 2010. Imágenes al margen: cotidianidad en la Valencia de los siglos XIV al XVIII. Valencia: Museu Valencià de la Il-lustració i de la Modernitat. 
Cotarelo y Mori, Emilio. 2004. Diccionario biográfico y bibliográfico de calígrafos españoles. Madrid: Visor Libros.

Cruz Pascal, Paloma. 2001-2002. "Ejercicios de escritura y otros elementos de la guarda en el códice de Juan de Bondreville, siglo XV". Miscelánea Medieval Murciana:23-38.

Doede, Werner. 1958. Bibliographie deutscher Schreibmeisterbücher von Neudörffer bis 1800. Hamburg: Ernest Hauswedell \& Co.

Egido, Aurora. 2003. "Los manuales de escribientes y la teoría de la escritura (siglos XVI-XVIII)", en La voz de las letras en el Siglo de Oro, 17-50. Madrid: Abada.

Els ninots de l'escrivà, dibuixats frivolament en seriosos documents notarials: catàleg de l'exposició. 1999. Girona, Arxiu Històric de Girona.

Fabré, Daniel. 1993. Écritures ordinaries. París: Centre Georges Pompidou, Bibliothèque publique d'information 11-30.

Fabré, Daniel. 1997. Par ècrit: ethnologie des ècritures quotidiennes. París: Editions de la Maison des Sciences de l'homme.

Fleming, Juliet. 2016. Cultural Graphology: writing after Derrida. Chicago: University Press.

Frasso, Giuseppe. 1995. "Libri a stampa postillati: riflessioni suggerite da un catálogo". Aevum LXIX: 617-640.

Gimeno Blay, Francisco M. 1995. "Aprender a escribir en la Península Ibérica: de la Edad Media al Renacimiento”, en Escribir y leer en Occidente, editado por Armando Petrucci y Francisco M. Gimeno Blay, 125-144. Valencia: Seminario Internacional de Estudios sobre la Cultura Escrita José Trenchs Odena (Universidad de Valencia).

Gimeno Blay, Francisco M. 2010. "Garabatear, okupar espacios de escritura”, en Imágenes al margen. Cotidianeidad en la Valencia de los siglos XIV al XVIII, 25-28. Valencia: Museu Valencià de la Il-lustració i de la Modernitat.

Gutiérrez Cabero, Ángel Manuel. 2015. "La enseñanza de la caligrafía en España a través de los Artes de Escribir de los siglos XVI al XX: la construcción de un estilo de escritura". Tesis doctoral, Universidad Complutense de Madrid. CreateSpace Independent Publishing Platform.

Heitzmann, Christian. 2015. "Marginalien in Alten Drucken”. Augusta: Wolfenbütteler Bibliotheks-Informationen 40: 18-19.

Infantes, Víctor y Ana Martínez Pereira. 2003. De las primeras letras. Cartillas españolas para enseñar a leer de los siglos XVII y XVIII. Salamanca: Universidad, 2 vols.

Iser, Wolfgang. 1980. "Interaction between text and reader", en The Reader in the text: essays on Audience and Interpretation, editado por Susan K. Suleiman e Inge Crossman, 106-119. N. Jersey: Princeton University Press.

Jackson, H. J. 2001. Marginalia: readers writing in books. Londres: Yale University Press.

Jahjah, Marc. 2014. "Les marginalia de lecture dans les «réseaux sociaux» du livre (2008-2014): mutations, formes, imaginaires”. Tesis doctoral, París, École doctorale de l'École des hautes études en sciences sociales.

Johnson, Alfred Forbes. 1950. Bibliography of italian Writing-Books of the XVI Century. London: Curwen Press.

Lucía Megías, José Manuel. 2002. “Una nueva página en la recepción de los libros de caballerías: las anotaciones marginales", en Libros de caballerías (de Amadís al Quijote). Poética, lectura, representación e identidad, editado por Eva Belén Carro, Laura Puerto y María Sánchez, 201-243. Salamanca: SEMYR. 
Martínez, María Victoria y Natalia Ortiz. 2018. Vea lo que bay en este libro. Santiago de Chile: Écfrasis.

Martínez Pereira, Ana. 2003-2004. "Los manuales de escritura de los Siglos de Oro: problemas bibliográficos”. Litterae: Cuadernos sobre cultura escrita 3-4: 133-159.

Martínez Pereira, Ana. 2004. "El «Arte de escrever» de Manuel Barata en el ámbito pedagógico de la segunda mitad del siglo XVI”. Península: revista de estudos ibéri$\cos 1: 235-250$.

Martínez Pereira, Ana. 2006. Manuales de escritura de los Siglos de Oro: repertorio crítico de obras manuscritas e impresas. Mérida: Editora Regional de Extremadura.

Montaner Frutos, Alberto y Diego Navarro. 2006. "Erotismo en el margen: sobre memoria manuscrita popular (Aragón, siglos XVI-XVII)”, en La literatura popular impresa en España y en la América colonial: formas y temas, géneros, funciones, difusión, historia y teoría, dirigido por Pedro Manuel Cátedra García Salamanca, 523-542. Salamanca: SEMYR.

Morison, Stanley. 1962. Calligraphy: 1535-1885. A selection of Seventy-two Writing Books and Specimens from the Italian, French, Low Countries and Spanish Schools [...]. Milano: La Bibliofilia.

Nakládalová, Iveta. 2013. La lectura docta en la primera edad moderna (1450-1650). Madrid: Abada.

Navarro Bonilla, Diego. 2003. "Las huellas de la lectura: marcas y anotaciones manuscritas en impresos de los siglos XVI a XVIII", en Libro y lectura en la Península Ibérica y América: siglos XIII a XVIII, coordinado por Antonio Castillo, 243-288. Valladolid: Consejería de Cultura y Turismo.

Navarro Bonilla, Diego. 2006. "Leer y escribir al margen: anotaciones manuscritas en impresos antiguos", en Imprenta, libros y lectura en la España del Quijote, editado por José Manuel Lucía Megías, 429-446. Madrid: Imprenta Artesanal.

Pearson, David. 1994. Provenance Research in Book History: A Handbook. London: British Library.

Petrucci, Armando. 1999. Alfabetismo, escritura, sociedad. Barcelona: Gedisa.

Rico y Sinobas, M.1903. Diccionario de calígrafos españoles. Madrid: Real Academia Española.

Rosenthal, Bernard M. 1997. The Rosenthal Collection of printed books with manuscript annotations: a catalog of 242 editions mostly before 1600, annotated by contemporary or near-contemporary readers. New Haven: Yale University.

Rosenthal, Bernard M. 1999. "Cataloguing Manuscript annotations in printed books: some thoughts and suggestions from the other side of the academic fence”, en Anatomie Bibliologiche: saggi di storia del libro per il centenario de «la bibliofilia», editado por Luigi Balsamo y Pierangelo Belletini, 583-595. Firenze: Olschki.

Sáez, Carlos. 1998. "Escrituras ordinarias y transmisión cultural en la Edad Media", en Pensamiento medieval hispano: homenaje a Horacio Santiago-Otero, vol. 1, 627644. Madrid: Consejo Superior de Investigaciones Científicas.

Stoddard, Roger. 1985. Marks in books: illustrated and explained. Cambridge: Houghton Library at Harvard University. 
Para citar este texto:

Navarro Bonilla, Diego y Cristina Muñoz Vela. 2021. "Libros de letras y letras en el libro: anotaciones caligráficas en manuales y artes de escritura (siglos XVI-XVIII)". Investigación Bibliotecológica: archivonomía, bibliotecología e información 35 (87): 107-128.

http://dx.doi.org/10.22201/iibi.24488321xe.2021.87.58298

\section{Anexo}

Listado de autores y obras analizadas. Datos procedentes del Catálogo Colectivo del Patrimonio Bibliográfico Español:

1. Anduaga y Garimberti, Joseph. Arte de escribir por reglas y sin muestras [...], Madrid, Imprenta Real, 1781, 1795.

2. Anduaga y Garimberti, Joseph. Compendio del arte de escribir por reglas y sin muestras [...], Madrid, Imprenta Real, 1791, 1805, 1822 (Imp. Nacional).

3. Asensio y Mejorada, Francisco. Geometría de la letra romana mayúscula y minúscula, Madrid, Andrés Ramírez, 1780.

4. Aznar de Polanco, Juan Claudio. Arte nuevo de escribir por preceptos geométricos y reglas matemáticas, Madrid, Herederos de Manuel Ruiz de Murga, 1719.

5. Bueno, Diego. Arte nuevo de enseñar a leer, escrivir y contar príncipes y señores, Zaragoza, Domingo Gascón, 1690, 1700.

6. Casanova, José de. Primera parte del Arte de escrivir todas formas de letras, Madrid, Diego Díaz de la Carrera, 1650.

7. Cuesta, Juan de la. Libro y Tratado para enseñar leer y escrivir brevemente y con gran facilidad con reta pronunciación y verdadera ortographia todo Romance Castellano, Alcalá, Juan Gracián, 1589.

8. Díaz Morante, Pedro. Arte de escrevir inventada con el fabor de Dios, Madrid, s.n., 1616.

9. Díaz Morante, Pedro. Segunda parte del Arte de escrivir, Madrid, Luis Sánchez, 1624.

10. Díaz Morante, Pedro. Tercera parte del arte nueva de escrivir, Madrid, Imprenta Real, 1629.

11. Díaz Morante, Pedro. Quarta parte del arte nueva de escrevir Pedro Diaz Morante, [Madrid], [s.n.], 1631, 1645, 1654.

12. Flórez, Pedro. Méthodo del arte de escrivir, Madrid, Luis Sánchez, 1614. 
13. Icíar, Juan de. Recopilación subtilissima, intitulada Ortograpbia pratica [...], Zaragoza, Bartolomé de Nájera, 1548.

14. Icíar, Juan de. Arte subtilissima por la qual se enseña a escrevir perfectamente, Zaragoza, Pedro Bernuz, 1550, 1553, 1555.

15. Icíar, Juan de. Libro subtilissimo por el qual se enseña a escreuir y contar perfectamente: el qual lleua el mesmo horden que lleua vn maestro con su discipulo, Zaragoza [...], 1559, 1564, 1566.

16. Lucas, Francisco. Arte de escrevir [...], Madrid, Alonso Gómez, 1577, 1580, 1608.

17. Madariaga, Pedro de. Libro subtilissimo intitulado Honra de Escriuanos, Valencia, Juan de Mey, 1565.

18. Madariaga, Pedro de. Arte de escribir ortografía de la pluma y bonra de los profesores de este magisterio [...], Madrid, Antonio de Sancha, 1777.

19. Ortiz, Lorenzo. El maestro de escrivir: la theorica y la práctica para aprender y para enseñar este utilissimo arte, Venecia, Paolo Baglioni, 1696.

20. Pérez, Ignacio. Arte de escrevir con cierta industria e invención para bazer buena forma de letra, y aprenderlo con facilidad, Madrid, Imprenta Real, 1599.

21. Rodríguez, Cristóbal. Bibliotheca universal de la polygraphia española, Madrid, Antonio Marín, 1738.

22. Santiago Palomares, Francisco Xavier de. Arte nueva de escribir [...], Madrid, Antonio de Sancha, 1776.

23. Santiago Palomares, Francisco Xavier de. El maestro de leer [...], Madrid, Antonio de Sancha, 1786.

24. Servidori, Domingo María de. Reflexiones sobre la verdadera arte de escribir [...], Madrid, Imprenta Real, 1789. 